\title{
Competitiveness Of Advanced Technologies For Production Of Electricity And Alternative Liquid Fuels
}

\author{
Elina Tyurina ${ }^{1, *}$, Aleksandr Mednikov ${ }^{1}$, and Svetlana Sushko ${ }^{2}$ \\ ${ }^{1}$ Melentiev Energy Systems Institute of Siberian Branch of the Russian Academy of Sciences, 130, Lermontov str., Irkutsk, 664033, \\ Russia \\ ${ }^{2}$ Irkutsk National Research Technical University, 83, Lermontov str., Irkutsk, 664074, Russia
}

\begin{abstract}
Technical and economic aspects of synthetic liquid fuel and electric power combined production within one energy-technology installation (ETI) are considered. The range of prices for alternative liquid fuel (ALF) produced by the installations, depending on the cost of consumed fuel, price of supplied electric power and level of capital investments, has been ascertained. The studies made suggest the conclusion that combined production of dimethyl ether is more efficient from the energy and economic viewpoints than methanol production. Besides, a certain level of oil prices was identified, its excess implying that production of ALF, i.e. dimethyl ether, will be more economically efficient than production of motor fuel from oil.
\end{abstract}

\section{Introduction}

Abrupt increase in oil prices is observed in the course of recent few years, stemming from a number of reasons, i.e. reduction of cheap oil reserves, incremental consumption in the developing countries including China and India, etc.

Therefore, identification of oil price level, at which motor alternative liquid fuel (ALF) made of natural gas and coal becomes competitive with motor fuel produced from oil, is of considerable interest.

Methanol $\left(\mathrm{CH}_{3} \mathrm{OH}\right)$ and dimethyl ether (DME $\mathrm{CH}_{3} \mathrm{OCH}_{3}$ ) are currently considered the most promising types of ALF. Their catalytic production features a high level of selectivity, while their combustion products feature high enough ecological compatibility. Research aimed at studying the technologies for ALF production [1-4] conducted by Energy Systems Institute (ESI), Siberian Branch of Russian Academy of Sciences, conjointly with Topchiev Institute of Petrochemical Synthesis of Russian Academy of Sciences indicates that it is advisable to combine large-scale ALF production from coal and natural gas and electric power generation. It will permit utilizing essential amount of heat and combustible waste yielded by ALF production. Meanwhile, energy and economic efficiency of the combined production proved much higher than that of separate processes.

In this study the costs of methanol and dimethyl ether co-produced with electric power at energytechnology installations (ETI) are determined, allowance made for uncertainty of capital investments, prices for consumed fuel and produced electric power. Then, relying on ratios between motor fuel and oil prices, the oil prices can be found, at which the fuel produced from coal and natural gas can compete with fuel made from oil.

\section{Studies of ETI for ALF synthesis}

Mathematical models of energy-technology installations have been used during the studies, the installation being modeled by three outline blocks (fig. 1): synthesis gas production block (1), ALF synthesis block (II) and energy block (III).

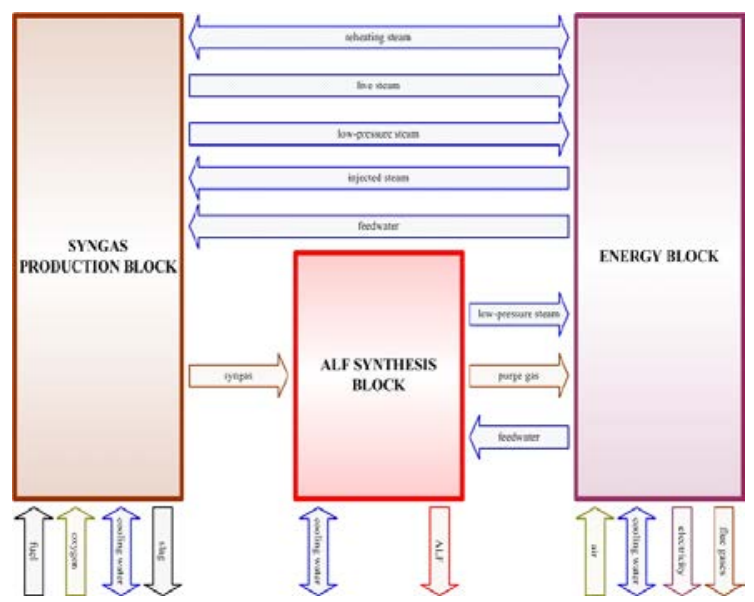

Fig. 1. A simplified diagram of material flows within ETI for ALF synthesis and electric power production.

Gasification of solid fuel or natural gas conversion yielding a mixture of hydrogen and carbon oxide (synthesis gas) are conducted within block I. Besides, the synthesis gas is cooled within the block in the 
system of gas generator or converter heat exchangers and then it is treated (if necessary) for ash and sulfur compounds. Steam, generated due to heat released by the gas cooling, enters the energy block steam turbine for electric power generation. Catalytic synthesis of methyl alcohol or dimethyl ether takes place in block II, meanwhile, low-pressure steam is generated by intermediate heat exchangers of the synthesis reactors designed for removal of the reaction heat. The steam enters the low-pressure section of the steam turbine. Blast gas from the synthesis block enters the combustion chamber in block III, whence the combustion products are fed to electric power production by gas turbines. The block waste heat boiler generates high- and low-pressure steam fed to the steam turbine. It is noteworthy that ETI process flowsheets differ for DME and methanol synthesis, as there is a unit for DME, methanol and water separation in the ETI for DME synthesis, as well as recirculation of methanol formed during DME synthesis in the reactor. Fig. 2 by way of example shows a more detailed process flowsheet of ETI for DME synthesis from coal.

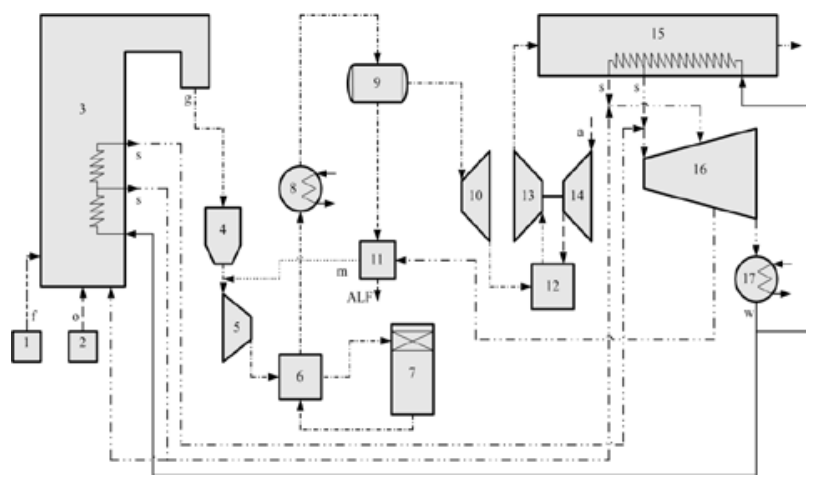

Fig. 2. Flow chart of ETI for dimethyl ether synthesis from coal. a - air, f - fuel, g - gas, w - water, s - steam, m methanol recirculation, o - oxygen, 1 - fuel preparation system, 2 - air separation system, 3 - gasifier, 4 - system of synthesis gas cleaning, 5 - compressor of syngas, 6 regenerative gas-to-gas heat exchanger, 7 - catalytic synthesis reactors, 8 - condenser, 9 - separator, 10 - expansion turbine, 11 - block of separation of water, methanol and DME, 12 combustion chamber of blast gases, 13 - gas turbine. 14 - air compressor, 15 - waste-heat boiler, 16-stcam turbine, 17 steam turbine condenser.

The energy-technology installations are complex engineering systems, their efficiency depending on a great number of parameters. Ascertaining of the installation optimal parameters, which could provide its utmost technical and economic efficiency, is a complicated problem. Its solution necessitating employment of special mathematical simulation and optimization methods.

Obviously, the resulting ALF/electric power ratio of the ETI is the main factor dictating the cost of all its blocks, its energy efficiency, technical and economic indices. The composition of gas mixture injected to natural gas converters or coal gas generators is the major parameter affecting the above ratio and determining the synthesis gas composition and number of reactors in the synthesis block, which, in its turn, characterizes the degree of synthesis gas conversion to
ALF. The following options of the installations were considered: ETI for methanol synthesis and electric power production from coal and natural gas and ETI for DME synthesis and electric power production from the same kinds of fuel. All the options were calculated for identical annual fuel consumption, i.e. $2.5 \mathrm{mln} t$ c.e., which corresponds to consumption of 2.2 bin $\mathrm{m}^{3}$ of natural gas and $4.5 \mathrm{mln}$ t of the Kanko-Achinsk coal.

While identifying the ETI optimal options, the problem of nonlinear mathematical programming was solved, which consists essentially in ascertaining the installation parameters, i.e. composition of gas injected to the gas generators or converter, amount of catalyst in the synthesis reactors, temperatures and pressures of working fluids of the combined-cycle plant, etc., which assure minimal prices of ALF produced with preset levels of internal rate of return on capital, prices for fuel consumed and electric power supplied, taking into account the physico-technical restraints of the installation parameters.

Table 1 provides basic technical and economic indices of the optimal option of coal and gas fueled ETI for methanol and DME synthesis, which have been obtained as a result of optimization studies using mathematical models of the relevant installations. It can be seen that the options of methanol and DME production differ essentially in terms of the products (ALF and electric power). Hence, installations for DME synthesis feature a higher level of ALF production (in the energy equivalent) compared to installations for methanol synthesis. In its turn, a ETI for methanol synthesis generates essentially higher amounts of electric power (1.5-3 times higher, depending on fuel consumed).

Table 1. Major technical and economic indices of ETI options for methanol or DME synthesis and electric power production

\begin{tabular}{|c|c|c|c|c|}
\hline \multirow{3}{*}{ Index } & \multicolumn{4}{|c|}{ ETI options } \\
\hline & \multicolumn{2}{|c|}{ natural gas } & \multicolumn{2}{|c|}{ coal } \\
\hline & \begin{tabular}{|c|}
$\mathrm{DME}$ \\
synthesis
\end{tabular} & $\begin{array}{l}\text { methanol } \\
\text { synthesis }\end{array}$ & \begin{tabular}{|c|}
$\mathrm{DME}$ \\
synthesis \\
\end{tabular} & $\begin{array}{l}\text { methanol } \\
\text { synthesis } \\
\end{array}$ \\
\hline $\begin{array}{l}\text { Annual natural fuel } \\
\text { consumption, mln } \\
\mathrm{m}^{3} \text { or thous. } \mathrm{t}\end{array}$ & \multicolumn{2}{|c|}{2200} & \multicolumn{2}{|c|}{4500} \\
\hline $\begin{array}{l}\text { Annual consumption } \\
\text { of equivalent fuel, } \\
\text { thous. t c.e. }\end{array}$ & \multicolumn{4}{|c|}{2500} \\
\hline \multicolumn{5}{|l|}{$\begin{array}{l}\text { Annual production } \\
\text { of methanol or } \\
\text { DME: }\end{array}$} \\
\hline $\begin{array}{l}\text { equivalent fuel, } \\
\text { thous. t c.e. }\end{array}$ & 1720 & 1400 & 1600 & 1350 \\
\hline $\begin{array}{l}\text { natural fuel, thous. } \\
\mathrm{t}\end{array}$ & 1745 & 1900 & 1625 & 1880 \\
\hline \multicolumn{5}{|l|}{ Power, MW: } \\
\hline steam turbine & 230 & 330 & 240 & 270 \\
\hline gas turbine & 60 & 160 & 110 & 145 \\
\hline in-house needs & 194 & 167 & 189 & 185 \\
\hline net & 90 & 320 & 150 & 225 \\
\hline $\begin{array}{l}\text { Annual electric } \\
\text { power supply, mln } \\
\text { kWh }\end{array}$ & 625 & 2200 & 1060 & 1560 \\
\hline
\end{tabular}




\begin{tabular}{|l|c|c|c|c|}
\hline $\begin{array}{l}\text { Capital investments, } \\
\text { \$ mln: }\end{array}$ & & & & \\
\hline $\begin{array}{l}\text { total investments } \\
\text { into installation }\end{array}$ & 908 & 934 & 1276 & 1252 \\
\hline block I & 218 & 218 & 576 & 576 \\
\hline block II & 482 & 392 & 448 & 378 \\
\hline block III & 208 & 324 & 252 & 298 \\
\hline $\begin{array}{l}\text { Exergy efficiency of } \\
\text { production methanol } \\
\text { or DME, \% }\end{array}$ & 71.9 & 66.8 & 69.2 & 61.7 \\
\hline
\end{tabular}

As there is essential uncertainty in prices for consumed fuel, produced ALF and electric power, as well as in prices for the materials and equipment of the energy-technology installations, the studies were conducted for different levels of the prices. The change in the level of capital investments to the installations was taken into account by using the factor of the investment rise in price multiplied by capital investments into basic options provided in table 1 . The factor presumably falls in the range of 1.0-1.5. The natural gas prices have been set at a level of $\$ 60-80$ per $1000 \mathrm{~m}^{3}$, coal prices being $\$ 30-50$ per $t$ c.e. The price of power supplied by ETI to power grid has been assumed to be $\$ 0.04-0.06 / \mathrm{kWh}$. The calculations using $15 \%$ internal rate of return on capital investments have been made. Table 2 shows prices for ALF produced by ETI.

Table 2. Dependence of prices for ALF produced by ETI on fuel, electric power and equipment prices, $\$ / t$ c.e.

\begin{tabular}{|c|c|c|c|c|c|c|}
\hline \multirow{4}{*}{$k_{\text {rise }}$} & \multirow{4}{*}{$\begin{array}{c}c_{\mathrm{t}}^{* *}, \\
\$ / 100 \\
0 \mathrm{~m}^{3} \\
\text { of } \\
\text { gas; } \\
\$ / 1 \mathrm{t} \\
c . e \text { of } \\
\text { coal }\end{array}$} & \multirow{4}{*}{$\begin{array}{c}C_{\mathrm{el}}{ }^{* * *}, \\
\mathrm{~h}\end{array}$} & \multicolumn{4}{|c|}{ ETI options } \\
\hline & & & \multicolumn{2}{|c|}{ natural gas } & \multicolumn{2}{|c|}{ coal } \\
\hline & & & DME & methano & DME & methano \\
\hline & & & $\begin{array}{c}\text { synthesi } \\
\text { s }\end{array}$ & $\begin{array}{c}\text { synthesi } \\
\text { s }\end{array}$ & $\begin{array}{c}\text { synthesi } \\
\text { s }\end{array}$ & $\begin{array}{c}\text { synthesi } \\
\text { s }\end{array}$ \\
\hline \multirow{4}{*}{1} & \multirow{2}{*}{$60(30)$} & 4 & 252 & 286 & 295 & 336 \\
\hline & & 6 & 248 & 254 & 280 & 310 \\
\hline & \multirow{2}{*}{$80(50)$} & 4 & 280 & 247 & 332 & 379 \\
\hline & & 6 & 273 & 286 & 318 & 350 \\
\hline \multirow{4}{*}{1.25} & \multirow{2}{*}{$60(30)$} & 4 & 295 & 342 & 365 & 415 \\
\hline & & 6 & 286 & 305 & 350 & 388 \\
\hline & \multirow{2}{*}{$80(50)$} & 4 & 325 & 384 & 402 & 457 \\
\hline & & 6 & 318 & 342 & 388 & 430 \\
\hline \multirow{4}{*}{1.5} & \multirow{2}{*}{$\begin{array}{c}60(30 \\
)\end{array}$} & 4 & 342 & 402 & 434 & 494 \\
\hline & & 6 & 332 & 365 & 415 & 467 \\
\hline & \multirow{2}{*}{$80(50)$} & 4 & 370 & 440 & 472 & 540 \\
\hline & & 6 & 362 & 402 & 457 & 514 \\
\hline
\end{tabular}

$* k_{\text {rise }}$ - rise in price of capital investments, ${ }^{* *} c_{\mathrm{t}}$ - consumed fuel price, ${ }^{* * *} c_{\mathrm{el}}$ - price of supplied electric power.

Evidently, the ALF prices, depending on combination of prices for gaseous and solid fuel, electric power, materials and equipment, are within the following ranges:

- \$248-370/t c.e. for ETI for DME synthesis from natural gas;

- \$254-440/t c.e. for ETI for DME synthesis from coal;

- \$280-472/t c.e. for ETI for methanol synthesis from natural gas;
- \$310-540/t c.e. for ETI for methanol synthesis from coal.

The lowest prices for ALF result from low price of consumed fuel, high price of supplied electric power and basic capital investments (rise in price factor equals 1), while the highest price for ALF is dictated by high price of fuel, low price for electric power and the highest rise in price of the capital investments.

The relation between price for motor fuel produced from oil and price for crude oil can be sufficiently accurately presented as:

$$
S_{M F}=k_{P R} \cdot S_{C O}+S_{P R}+P,
$$

where $S_{M F}$ - motor fuel price, $S_{C O}$ - crude oil price, $k_{P R}$ specific consumption of crude oil for production of a motor fuel unit, $S_{P R}$ - production costs of a motor fuel unit, $P$ - profit of the enterprises engaged in oil refining (per motor fuel unit). Bearing in mind analysis of the current price levels and oil refining costs, let us assume that $S_{M F}=\$ 400 / \mathrm{t}, k_{P R}=1.2 \mathrm{t}$ of oil per $\mathrm{t}$ of motor fuel, $\left(S_{P R}+P\right)=\$ 70 / \mathrm{t}$. Then synthetic motor fuel will be of equal value compared with fuel produced from oil, if the price for a unit of "natural" motor fuel equals the price of energy equivalent amount of synthetic liquid fuel. Let us assume that heat of combustion of one ton of natural motor fuel equals $1.43 \mathrm{t}$ c.e. The price ranges for crude oil, found on the basis of expression (1) and determined previously from the range of prices for ALF from natural gas and coal, at which ALF motor fuel is economically equal to motor fuel oil produced from oil, are provided in table 3 .

Table 3. Range of oil prices providing equal economic value of synthetic and "natural" motor fuel, \$/t (\$/barrel)

\begin{tabular}{|c|c|c|c|c|}
\hline \multirow{2}{*}{ Price } & \multicolumn{4}{|c|}{ ETI options } \\
\cline { 2 - 5 } & \multicolumn{2}{|c|}{ natural gas } & \multicolumn{2}{c|}{ coal } \\
\cline { 2 - 5 } & $\begin{array}{c}\text { DME } \\
\text { synthesis }\end{array}$ & $\begin{array}{c}\text { methanol } \\
\text { synthesis }\end{array}$ & $\begin{array}{c}\text { DME } \\
\text { synthesis }\end{array}$ & $\begin{array}{c}\text { methanol } \\
\text { synthesis }\end{array}$ \\
\hline Lowest & $238(34.1)$ & $246(35.2)$ & $280(40.0)$ & $319(45.6)$ \\
\hline Highest & $390(55.7)$ & $473(67.6)$ & $512(73.2)$ & $594(84.8)$ \\
\hline
\end{tabular}

\section{Conclusion}

Analysis of the crude oil prices shown in table 3 suggests the following conclusions.

1) Combined production of dimethyl ether features a higher energy and economic efficiency than methanol production. It stems from greater relative output of ALF and lower electric power production, which ensures high efficiency and lower specific capital costs.

2) It can be stated with a high enough justification that production of dimethyl ether from natural gas will be more efficient economically than production of motor fuel from oil at oil price in excess of $\$ 55 /$ barrel, while DME production from coal will be more effective at oil price in excess of $\$ 73 /$ barrel. 


\section{Acknowledgements}

This work was carried out at Melentiev Energy Systems Institute of Siberian Branch of the Russian Academy of Sciences and supported by Russian Foundation for Basic Research (RFBR) via grant № 18-08-01184 A. Part of the work is carried out within the framework of fundamental research program of the Russian Academy of Sciences for 2013-2020.

\section{References}

1. E.A. Tyurina, Perspectives in Energy. 6 (2002).

2. Kler A. M., Dekanova N. P., Tyurina E. A. et al. Thermal Power Systems: Optimization Studies (Novosibirsk Nauka, 2005)

3. A.M. Kler, E.A. Tyurina, Combustion plasma chemistry, 4 (2007)

4. A.M. Kler, E.A. Tyurina, A.S. Mednikov, V.V. Stepanov, International Journal of Low-Carbon Technologies, 5(4) (2010) 